\title{
AiMT
}

Advances in Military Technology

Vol. 15, No. 1, 2020, pp. 55-65

ISSN 1802-2308, eISSN 2533-4123

DOI 10.3849/aimt.01303

\section{Justification of the Optimal Composition of the Air Defense Troops Grouping}

\author{
O. Zahorka, I. Zahorka and S. Polishchuk* \\ National Defence University of Ukraine named after Ivan Cherniakhovskyi, Kyiv, Ukraine
}

The manuscript was received on 27 February 2019 and was accepted after revision for publication as research paper on 20 January 2020.

\begin{abstract}
:
The article deals with the problem of determining the number of antiaircraft missile systems of various types in grouping of Air Defense troops for the purpose of providing the required effectiveness of repelling the enemy air strikes on the objects and troops. The methodology of justification of ratio of different types of antiaircraft missile systems in the grouping of Air Defense troops using Lagrange's method of undetermined multipliers has been developed. This technique allows justifying a set of types of antiaircraft missile systems which will provide maximum effectiveness of the employment of grouping of Air Defense troops. This approach can also be used to justify the composition of mixed military formations of Air Defense.
\end{abstract}

\section{Keywords:}

antiaircraft missile system, grouping of Air Defense troops, Lagrange's method of undetermined multipliers, ratio of antiaircraft missile systems

\section{Introduction}

Typically, antiaircraft missile systems (AAMs) of different types which differ in tactical and technical characteristics [1-3] are usually used to form a grouping of Air Defense (AD) troops. It is well known that the effectiveness of the employment of the grouping of $\mathrm{AD}$ troops to repel air strikes on the objects and troops, as well as any system designed to engage the objects (targets), nonlinearly depends on the number and types of antiaircraft missile systems in it. It differs in different types of AAMs [2].

There is a well-known regularity: the more effective the functioning of the system, the more means are necessary for its further increase [2]. That is, it can be assumed that there is such a ratio of different types of AAMs that can provide the maximum effectiveness of employment of the grouping of AD troops. Therefore, the

${ }^{*}$ Corresponding author: Department of Antiaircraft Missile Troops, National Defence University of Ukraine named after Ivan Cherniakhovskyi, 28 Povitroflotskyi av., 03049 Kyiv, Ukraine. Phone: +380672789704,_E-mail: sergiy_pv@ukr.net 


\begin{tabular}{|c|c|c|c|}
\hline \multicolumn{4}{|c|}{ Nomenclature } \\
\hline$i$ & Type of the AAMs & $q$ & $\begin{array}{l}\text { Intensity of entering the targets in the } \\
\text { air defense zone }\end{array}$ \\
\hline$x_{i}$ & $\begin{array}{l}\text { Number of AAMs of } i \text {-type in the } \\
\text { grouping of AD troops }\end{array}$ & $P_{i}$ & $\begin{array}{l}\text { Probability of destroying the target of } \\
\text { the AAMs of } i \text {-type }\end{array}$ \\
\hline$n$ & $\begin{array}{l}\text { Number of AAMs types in the group- } \\
\text { ing of AD troops }\end{array}$ & $N_{\text {tch, } i}$ & $\begin{array}{l}\text { Number of target channels of the } \\
\text { AAMs of } i \text {-type }\end{array}$ \\
\hline$M_{i}\left(x_{i}\right)$ & $\begin{array}{l}\text { Mathematical expectation of the } \\
\text { number of targets that can be de- } \\
\text { stroyed } x_{i} \text { AAMs of } i \text {-type }\end{array}$ & $L_{\mathrm{w}}, L_{\mathrm{d}}$ & $\begin{array}{l}\text { Width and depth of the area of re- } \\
\text { sponsibility of the grouping of AD } \\
\text { troops }\end{array}$ \\
\hline$K_{\text {part } . i}$ & $\begin{array}{l}\text { Coefficient of AAMs participation } \\
\text { rate of } i \text { - type in repelling the enemy } \\
\text { air strike }\end{array}$ & $\begin{array}{l}b \\
a_{i}\end{array}$ & $\begin{array}{l}\text { Power } \\
\text { Parameter of the power function }\end{array}$ \\
\hline$N$ & $\begin{array}{l}\text { Total number of AAMs in the group- } \\
\text { ing of AD troops }\end{array}$ & $t_{\text {fir }, i}$ & $\begin{array}{l}\text { Average time of firing the target of } \\
\text { AAMs of } i \text {-type }\end{array}$ \\
\hline$M^{\text {need }}$ & $\begin{array}{l}\text { Value of the mathematical expecta- } \\
\text { tion of the number of targets that } \\
\text { must be destroyed by the grouping of } \\
\mathrm{AD} \text { troops in the repelling of the } \\
\text { enemy air strikes }\end{array}$ & $R_{i}$ & $\begin{array}{l}\text { Average radius of the defeat zone of } \\
\text { the AAMs of } i \text {-type (it is assumed } \\
\text { that the horizontal defeat zone of the } \\
\text { AAMs is a circle) }\end{array}$ \\
\hline$m$ & Number of targets in a strike & $\lambda$ & Lagrange's undetermined multiplier \\
\hline
\end{tabular}

definition of the ratio of different types of AAMs is an important practical task, the solution of which must be done in creation of the grouping of AD troops.

\section{Preliminaries and Related Works}

It is evident that the main task of the grouping of $\mathrm{AD}$ troops is to provide the required effectiveness of repelling air strikes on the objects and troops [1-12]. Thus, in order to provide such effectiveness in creation of the grouping of AD troops, the task of determining the required number of forces and means, in particular the AAMs, is relevant. The required amount of AAMs to repel enemy air strikes is usually determined by the results of evaluation of the required effectiveness of $\mathrm{AD}$ troops.

In the papers [1,3-8] an analysis of existing and perspective air defense systems was carried out. However, the methodological theses for estimating the correlation of different types of AAMs in the grouping of AD troops are not considered. In [2] the task is to determine the rational number of target channels of various types of AAMs in the grouping of $\mathrm{AD}$ troops, depending on the effectiveness of their combat employment. However, the methodological guidelines for determining the number of different types of AAMs are not given in the work.

In $[9,10]$ the theoretical bases of synthesis of adaptive structures of the antiaircraft missile artillery system support are described. In addition, questions of determination of composition and operational structure of $\mathrm{AD}$ grouping, structure of combat orders of units (forces) of antiaircraft missile troops (AAMt) are examined. In [11], the methodology of rational structure of the antiaircraft missile and artillery support of the AD grouping of the Land forces in the Operational zone (area) is given. This method provides prediction of the effectiveness of the antiaircraft missile and artillery support, as well as taxonomic evaluation and direction of the formation of the most effective vector of parameters of the antiaircraft missile and artillery support of 
the $\mathrm{AD}$ grouping of the Land forces in the Operational zone (area), which defines a rational version of the structure of the antiaircraft missile and artillery support of AD grouping of the Land forces in the Operational zone (area). In [12] a methodology for pre-justification of the required composition of the AAMs of grouping of Air Defense troops, based on the compliance of the combat capabilities of the AAMs with the number and capabilities of the means of air attack expected in the strike is suggested. However, these techniques do not take into account the possibility of increasing the required efficiency of $\mathrm{AD}$ due to the ratio of $\mathrm{AAMs}$ of different types in the grouping of $\mathrm{AD}$ troops and, as a consequence, the possibility of reducing their number.

Thus, the task of determining the ratio of different types of AAMs in the grouping of $\mathrm{AD}$ troops to provide the required effectiveness of the repelling the enemy air strikes on the objects and troops requires further research.

The purpose of the article is to develop the main provisions of the methodology for justification of the ratio of various types of AAMs in the grouping of AD troops.

\section{Methodology Description and Basic Mathematical Equations}

The mathematical expectation of the number of targets that can be destroyed by the grouping of $\mathrm{AD}$ troops is determined by the amount

$$
M=\sum_{i} M_{i}\left(x_{i}\right) K_{\text {part. } i}, i=\overline{1, n} .
$$

It is necessary to define a set of AAMs of each $i$-type $x_{i}(i=\overline{1, n})$, which provides maximum mathematical expectation $M$ with the total number of AAMs in the grouping of AD troops

$$
N=\sum_{i} x_{i}, \quad i=\overline{1, n}
$$

In this case, the following condition must be met: $M \geq M^{\text {need }}$.

This problem can be solved by enumerating of possibilities of $x_{i}$, where a large number of variants of the grouping of AD troop, as well as considerable time, are required to be examined. Taking into consideration the nonlinearity of dependencies $M_{i}\left(x_{i}\right)=f\left(x_{i}\right)$, Lagrange's method of undetermined multipliers can be used to solve such a problem [13-14].

The block diagram of the methodology for justifying the ratio of different types of AAMs in the grouping of AD troops is shown in Fig. 1.

The process that takes place in the air defense system during the repulsion of an air strike is usually considered as a continuous Markov chain (the Markov process with discrete states of the system and continuous time). So determination of the mathematical expectation of the number of targets that can be destroyed by the AAMs of $i$ - type $M_{i}\left(x_{i}\right)$ when changing their number in the grouping of AD troops may be accomplished by using mass service theory methods, in particular the method used to evaluate the mass service system with refusals. In such case, according to [15-16], the mathematical expectation $M_{i}\left(x_{i}\right)$ for AAMs with a small defeat zone is determined by the formula

$$
M_{i}\left(x_{i}\right)=m P_{i}\left(1-\frac{\left(q t_{\mathrm{fir}, i}\right)^{x_{i}}}{x_{i} !} / \sum_{k=0}^{x_{i}} \frac{\left(q t_{\mathrm{fir}, i}\right)^{k}}{k !}\right) .
$$


Determination for calculating the total number and the amount of types of AAMs in the grouping of Air Defense troops

Determination of the dependencies of the mathematical expectation of the number of targets that can be destroyed by each type of AAMs on their number in the grouping of Air Defense troops Determination of empirical functions for each type of AAMs by approximating
the obtained dependencies

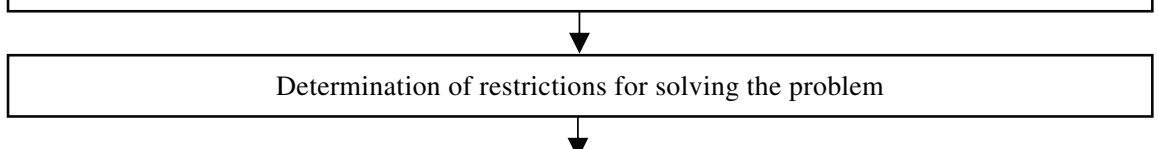

Formation of Lagrange's function for finding the maximum of mathematical expectation for the number of targets that can be destroyed by the grouping of Air Defense troops

Formation of the system of differential equations to find the conditional extremum of a function that determines the mathematical expectation of the number of targets that can be destroyed by the grouping of Air Defense troops

Solving the system of differential equations in order to obtain the value of an undetermined Lagrange's multiplier

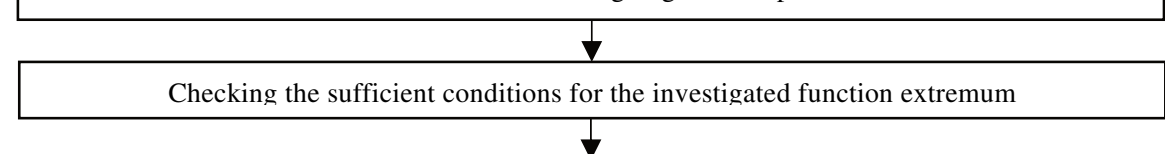

Determination of a set of types of AAMs that provide maximum effectiveness of the grouping of Air Defense troops employment

Determination of the coefficient of participation of each type of AAMs in repelling the enemv air strike

Determination of the mathematical expectation of the number of targets that can be destroyed by the grouping of Air Defense troops, taking into account the coefficient of participation of each type of AAMs

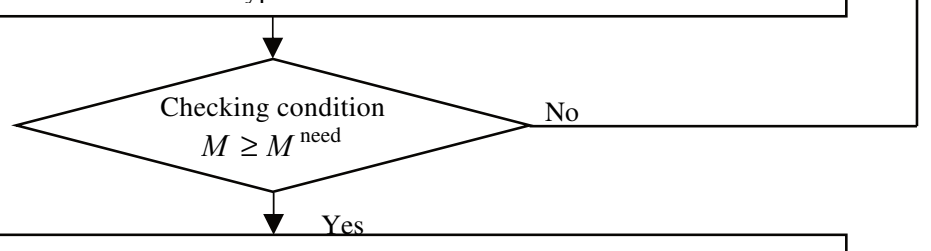

The use of a defined set of AAMs types as a source information for the formation of the grouping of Air Defense troops

Fig. 1 Structural scheme of the methodology of justification the ratio of different types of AAMs in the grouping of Air Defense troops 
For multichannel AAMs, the value $x_{i}$ should correspond to the total number of target channels of complexes of this type in the grouping of AD troops.

As an example in Tab. 1, the results of calculations of mathematical expectations $M_{i}\left(x_{i}\right)$ are shown according to Eq. (3) where $m=10$ targets, $P_{i}=0.5, q=2$ targets $/ \mathrm{min}$, and values $t_{\mathrm{fir}, 1}=1 \mathrm{~min}, t_{\mathrm{fir}, 2}=1.5 \mathrm{~min}, t_{\mathrm{fir}, 3}=2 \mathrm{~min}, t_{\mathrm{fir}, 4}=3 \mathrm{~min}$. Specified amount of AAMs in the grouping of AD troops is $N=10$.

Tab. 1 Results of calculations of mathematical expectations of the number of targets that can be destroyed by different types of AAMs and their approximation by power functions

\begin{tabular}{|c|c|c|c|c|c|c|c|c|}
\hline \multirow{4}{*}{$x_{i}$} & \multicolumn{8}{|c|}{ Types of AAMs } \\
\hline & \multicolumn{2}{|c|}{1} & \multicolumn{2}{|c|}{2} & \multicolumn{2}{|c|}{3} & \multicolumn{2}{|c|}{4} \\
\hline & \multicolumn{2}{|c|}{$t_{\mathrm{fir}, 1}=1 \mathrm{~min}$} & \multicolumn{2}{|c|}{$t_{\mathrm{fir}, 2}=1.5 \mathrm{~min}$} & \multicolumn{2}{|c|}{$t_{\mathrm{fir}, 3}=2 \mathrm{~min}$} & \multicolumn{2}{|c|}{$t_{\mathrm{fir}, 4}=3 \mathrm{~min}$} \\
\hline & $M_{1}$ & $M_{1}^{*}$ & $M_{2}$ & $M_{2}^{*}$ & $M_{3}$ & $M_{3}^{*}$ & $M_{4}$ & $M_{4}^{*}$ \\
\hline 1 & 1.65 & 2.61 & 1.25 & 1.97 & 1.00 & 1.43 & 0.71 & 1.10 \\
\hline 2 & 3.00 & 3.21 & 2.35 & 2.65 & 1.92 & 2.14 & 1.40 & 1.73 \\
\hline 3 & 3.95 & 3.62 & 3.27 & 3.16 & 2.74 & 2.70 & 2.05 & 2.27 \\
\hline 4 & 4.53 & 3.96 & 3.97 & 3.57 & 3.45 & 3.20 & 2.65 & 2.74 \\
\hline 5 & 4.82 & 4.23 & 4.45 & 3.94 & 4.00 & 3.64 & 3.20 & 3.18 \\
\hline 6 & 4.94 & 4.47 & 4.74 & 4.26 & 4.41 & 4.04 & 3.67 & 3.59 \\
\hline 7 & 4.98 & 4.68 & 4.89 & 4.55 & 4.69 & 4.42 & 4.07 & 3.97 \\
\hline 8 & 5.00 & 4.87 & 4.96 & 4.82 & 4.85 & 4.78 & 4.39 & 4.34 \\
\hline 9 & 5.00 & 5.04 & 5.00 & 5.06 & 4.93 & 5.11 & 4.62 & 4.69 \\
\hline 10 & 5.00 & 5.21 & 5.00 & 5.30 & 5.00 & 5.43 & 4.78 & 5.02 \\
\hline $\begin{array}{l}\text { Power } \\
\text { function }\end{array}$ & \multicolumn{2}{|c|}{$M_{1}^{*}=2.61 x_{1}^{0.30}$} & \multicolumn{2}{|c|}{$M_{2}^{*}=1.97 x_{2}^{0.43}$} & \multicolumn{2}{|c|}{$M_{3}^{*}=1.43 x_{3}^{0.58}$} & \multicolumn{2}{|c|}{$M_{4}^{*}=1.10 x_{4}^{0.66}$} \\
\hline
\end{tabular}

It is evident that when increasing the number of AAMs of the $i$-type $x_{i}$, the mathematical expectation $M_{i}\left(x_{i}\right)$ cannot exceed the product of the probability of destroying the target by their number in a strike $\left(m P_{i}\right)$.

To use Lagrange's method of undetermined multipliers in order to determine the optimal ratio of the different types of AAMs in the grouping of AD troops, it is necessary to have the functions $M_{i}\left(x_{i}\right)=f\left(x_{i}\right)$. It is known that in natural science many regularities are expressed by means of power functions $y=a x^{b}$. The power function can be approximated by the mathematical expectations of the number of targets that are destroyed by the AAMs of $i$-type (Tab. 1). Then the mathematical expectation is

$$
M_{i}^{*}\left(x_{i}\right)=a_{i} x_{i}^{b_{i}} \text {. }
$$

Function Eq. (4) for $1>b_{i}>0$ is convexity in the top. Lines that correspond to the power function are sometimes called polytropic lines.

The selection of the power function can be done in the form of equal sums [17]. To do this, all values (points) $x_{i}$ are divided into two equal groups (in our case, in two groups by $N / 2=5$ points). A system of equations is formed

$$
\begin{gathered}
a_{i}\left[1+2^{b_{i}}+3^{b_{i}}+\ldots+\left(\frac{N}{2}\right)^{b_{i}}\right]=\sum_{x_{i}=1}^{N / 2} M\left(x_{i}\right), \\
a_{i}\left[\left(\frac{N}{2}+1\right)^{b_{i}}+\left(\frac{N}{2}+2\right)^{b_{i}}+\ldots+N^{b_{i}}\right]=\sum_{x_{i}=N / 2+1}^{N} M\left(x_{i}\right) .
\end{gathered}
$$


According to the Tab. 1 for the first type of AAMs which has $t_{\mathrm{fir}, 1}=1 \mathrm{~min}$ the system of equations has the form

$$
\begin{aligned}
a_{1}\left(1+2^{b_{1}}+3^{b_{1}}+4^{b_{1}}+5^{b_{1}}\right) & =\sum_{x_{i}=1}^{5} M\left(x_{i}\right)=17.95, \\
a_{1}\left(6^{b_{1}}+7^{b_{1}}+8^{b_{1}}+9^{b_{1}}+10^{b_{1}}\right) & =\sum_{x_{i}=6}^{10} M\left(x_{i}\right)=24.92 .
\end{aligned}
$$

The indicator of the degree of the selected function $b_{i}$ is determined by dividing the equations of the system Eq. (5). This excludes the unknown $a_{i}$. So we get the function

$$
\Phi\left(b_{i}\right)=\frac{\left(\frac{N}{2}+1\right)^{b_{i}}+\left(\frac{N}{2}+2\right)^{b_{i}}+\ldots+N^{b_{i}}}{1+2^{b_{i}}+\ldots+\left(\frac{N}{2}\right)^{b_{i}}}=\frac{\sum_{x_{i}=N / 2+1}^{N} M\left(x_{i}\right)}{\sum_{x_{i}=1}^{N / 2} M\left(x_{i}\right)} .
$$

For our case we obtain the equation

$$
\Phi\left(b_{1}\right)=\frac{6^{b_{1}}+7^{b_{1}}+8^{b_{1}}+9^{b_{1}}+10^{b_{1}}}{1+2^{b_{1}}+3^{b_{1}}+4^{b_{1}}+5^{b_{1}}}=1.39 .
$$

The solution of this equation can be carried out by a graphical method. To do this, several function values are calculated $\Phi\left(b_{1}\right): \Phi(0)=1.0 ; \Phi(0.25)=1.31$; $\Phi(0.5)=1.68 ; \Phi(0.75)=2.13 ; \Phi(1.0)=2.66$ and the graph is constructed, as shown in Fig. 2.

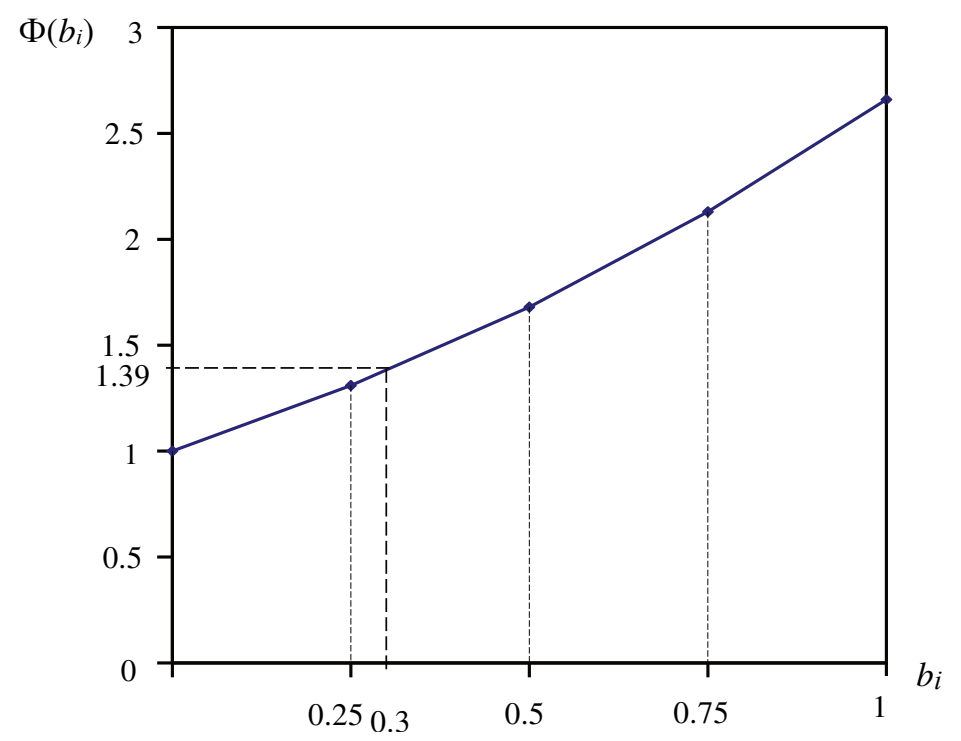

Fig. 2 The graph of the function $\Phi\left(b_{i}\right)$

Then, the indicator of the degree of function $b_{1}$ is determined using Fig. 2. For our 
case when $\Phi\left(b_{1}\right)=1.39$ (Eq. (8)), $b_{1}=0.30$.

The parameter of the power function $a_{i}$ is found by solving the first equation of the system Eq. (5). As an example that is examined, $a_{1}=2.61$. Thus we get own function

$$
M_{1}^{*}\left(x_{1}\right)=2.61 x_{1}^{0.30} \text {. }
$$

Similarly, power functions are determined for other types of AAMs; the results are shown in Tab. 1.

It should be noted that the dependence of the mathematical expectation on the number of targets that may be destroyed on the number of AAMs of $i$-type in the grouping of Air Defense troops can be approximated by functions of another type.

Applying Lagrange's method of undetermined multipliers to find the extremum of a function $M=\sum_{i} M_{i}^{*}\left(x_{i}\right), i=\overline{1, n}$, the ratio is formed

$$
H(\boldsymbol{x}, \lambda)=\sum_{i} a_{i} x_{i}^{b_{i}}-\lambda \sum_{i}\left(x_{i}-N\right), i=\overline{1, n}
$$

The system of differential equations for finding the conditional extremum of a function $M=\sum_{i} M_{i}^{*}\left(x_{i}\right)$ is

$$
\frac{\partial H(\boldsymbol{x}, \lambda)}{\partial x_{i}}=\frac{\partial \sum_{i} a_{i} x_{i}^{b_{i}}}{\partial x_{i}}-\frac{\partial \lambda \sum_{i}\left(x_{i}-N\right)}{\partial x_{i}}=0 .
$$

This system is supplemented by the equation

$$
\sum_{i} x_{i}-N=0
$$

In this way $n+1$ equations are obtained, which allows solving the problem with $n+1$ unknown $x_{i}, \lambda$.

Lagrange's method of undetermined multipliers gives only the necessary conditions for the existence of a conditional extremum for a continuous function. Therefore, the value of the obtained functions must be checked using the sufficient conditions of the extremum of the function of many variables. For this purpose, the second derivative functions are analyzed, on the basis of which the fulfillment of the Sylvester condition $[13,18]$ is checked.

Adequate conditions for the function extremum existence are determined by the results of an analysis of the matrix $\mathbf{A}=\left(a_{i j}\right)$ whose elements are coefficients $a_{i j}$, that are determined by the relation

$$
a_{i j}=\frac{\partial^{2} H(\boldsymbol{x}, \lambda)}{\partial x_{i} \partial x_{j}}=\frac{\partial^{2} H(\boldsymbol{x}, \lambda)}{\partial x_{j} \partial x_{i}}=a_{j i}, i=j=\overline{1, n} .
$$

The values of $\Delta_{i}$ are determined from the matrix $A=\left(a_{i j}\right)$ :

$$
\Delta_{2}=a_{11}, \Delta_{2}=\left|\begin{array}{ll}
a_{11} & a_{12} \\
a_{21} & a_{22}
\end{array}\right|, \cdots, \Delta_{n}=\left|\begin{array}{cccc}
a_{11} & a_{12} & \cdots & a_{1 n} \\
a_{21} & a_{22} & \cdots & a_{2 n} \\
\vdots & \vdots & \ddots & \vdots \\
a_{n 1} & a_{n 2} & \cdots & a_{n n}
\end{array}\right| .
$$

By the Sylvester conditions [17], if all values are $\Delta_{i}>0$, the acquired values of the variables respond the function's minimum. If $\Delta_{i}$ have an odd order, 
$\Delta_{1}, \Delta_{3}, \Delta_{5}, \ldots<0$, and a pair order $\Delta_{2}, \Delta_{4}, \Delta_{6}, \ldots>0$, then the values of the obtained variables respond to the function's maximum. If the conditions above are not fulfilled, then the function has neither a maximum nor a minimum at the point that is considered.

As an example, let's examine the grouping of Air Defense troops, in which there can be three types of AAMs which are 2, 3, 4 (Tab. 1).

For the three types of AAMs, which correspond to the functions (Tab. 1): $M_{2}^{*}=1.97 x_{2}{ }^{0.43}, M_{3}^{*}=1.43 x_{3}{ }^{0.58}, M_{4}^{*}=1.10 x_{4}{ }^{0.66}$, the system of equations that is received has the form:

$$
\begin{gathered}
\frac{\partial H(\boldsymbol{x}, \lambda)}{\partial x_{3}}=0.85 x_{2}^{-0.57}-\lambda=0 \\
\frac{\partial H(\boldsymbol{x}, \lambda)}{\partial x_{3}}=0.83 x_{3}^{-0.42}-\lambda=0 \\
\frac{\partial H(\boldsymbol{x}, \lambda)}{\partial x_{4}}=0.73 x_{4}^{-0.34}-\lambda=0 .
\end{gathered}
$$

So: $x_{2}^{0.57}=\frac{0.85}{\lambda}, x_{3}^{0.42}=\frac{0.83}{\lambda}, x_{4}^{0.34}=\frac{0.73}{\lambda}$,

or $x_{2}=\frac{0.75}{\lambda^{1.75}}, x_{3}=\frac{0.64}{\lambda^{2.38}}, x_{4}=\frac{0.40}{\lambda^{2.94}}$.

Taking into consideration Eq. (12) $\frac{0.75}{\lambda^{1.75}}+\frac{0.64}{\lambda^{2.38}}+\frac{0.40}{\lambda^{2.94}}=10$. So $\lambda=0.447$, and the value is $x_{2}=2.74, x_{3}=3.72, x_{4}=3.54$. In accordance with the equations system (15), the matrix $\mathbf{A}=\left(a_{i j}\right)$ has the form:

$$
\mathbf{A}=\left(\begin{array}{ccc}
-0.48 x_{2}^{-1.57} & 0 & 0 \\
0 & -0.35 x_{3}^{-1.42} & 0 \\
0 & 0 & -0.25 x_{4}^{-1.34}
\end{array}\right)
$$

Hence $\Delta_{1}<0, \Delta_{2}>0, \Delta_{3}<0$, that is, sufficient conditions for the extremum of the investigated function are fulfilled. After rounding the results $x_{2}=3, x_{3}=4, x_{4}=3$.

Thus, in the grouping of AD troops, it is advisable to have three second-class AAMs, four AAMS of the third type, and three AAMs of the fourth type. Such a ratio of the AAMs types provides the maximum potential effectiveness of the grouping of AD troops. According to Tab. 1, the value of the extremum of the function $M=\sum M_{i}^{*}\left(x_{i}\right), i=\overline{1, n}$ equals to 8.63 .

The effectiveness of the grouping of AD troops, which can be realized during combat operations, is determined taking into account the coefficients of participation $K_{\text {part. } i}$ Eq. (1), which refers to the proportions of the AAMs of $i$-type, which take part in repelling the enemy air strikes. It is believed that the magnitude of the coefficient $K_{\text {part. } i}$ is proportional to the ratio of the total area of the defeat zones of the AAMs of $i$ - type to the area of responsibility of the grouping of AD troops [9]. The graphical representation of the coefficient $K_{\text {part. } i}$ is shown in Fig. 3. 


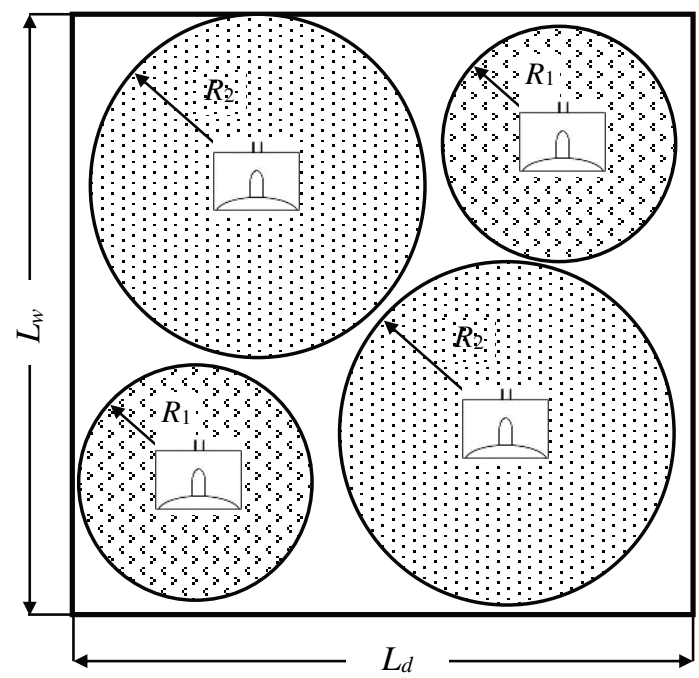

Fig. 3 Graphical representation of the coefficient $K_{\text {part } i}$

With an equal distribution of the means of air attack on the objects in the area of responsibility of the grouping of AD troops, $K_{\text {part. } i}$ can be determined by the formula

$$
K_{\text {part } . i}=\frac{\pi x_{i} N_{\mathrm{tch}, i} R_{i}^{2}}{L_{w} L_{d}}, K_{\text {part } . i} \leq 1 .
$$

As an example that is under consideration, when $R_{2}=10 \mathrm{~km}, R_{3}=15 \mathrm{~km}$, $R_{4}=20 \mathrm{~km}$, and $L_{\mathrm{w}} \times L_{\mathrm{d}}=50 \times 50 \mathrm{~km}$. By the Eq. (17) we get: $K_{\text {part.2 }}=0.38$, $K_{\text {part. } 3}=1.00, K_{\text {part. } 4}=1.00$.

The values $K_{\text {part. } 3}=1.00, K_{\text {part. }}=1.00$ are due to the large radius of the zones of defeat of the AAMs of the third and fourth type, in comparison with the responsibility area size of the grouping of AD troops, given in the example.

According to Tab. 1, for the example that is under consideration, mathematical expectation of the number of targets that can be destroyed by the grouping of Air Defense troops $M=\sum_{i} M_{i}\left(x_{i}\right) K_{\text {part } . i}, i=\overline{1, n}$ equals to 6.74. This exceeds the effectiveness of the grouping of Air Defense troops which employ only one of selected types of AAMs for $35-41 \%$ (according to Tab. 1, $M_{2}=5.0, M_{3}=5.0, M_{4}=4.78$ ).

This approach can also be used to justify the composition of mixed military formations of Air Defense.

\section{Conclusions}

The method of justification of the ratio of different types of AAMs in the grouping of Air Defense troops is proposed, taking into account the nonlinear nature of the change in the effectiveness of their number employment. The nonlinearity of changing the mathematical expectation of the number of targets that is destroyed by a particular type of AAMs is determined by the known dependence which is used to evaluate the efficiency of functioning of the multi-channel mass-service system with refusals. The optimal ratio of different types of AAMs in the grouping of Air Defense troops is determined using Lagrange's method of undetermined multipliers. 
The developed methodology should be used to justify the composition of the grouping of Air Defense troops, which may include different types of AAMs. In the future, it is advisable to improve the given method of obtaining dependencies of the effectiveness of the employment of different types of AAMs taking into account their number in the grouping of Air Defense troops.

\section{References}

[1] Field Manual No. FM 3-01.7. Air Defense Artillery Brigade Operations [on line]. Washington: Headquarters Department of the Army, 2000. 248 p. [cited 2018-1121]. Available from: https://www.bits.de/NRANEU/others/amd-us-archive/fm301.7\% 2800\%29.pdf

[2] TOROPCHYN, A.Y., KYRYCHENKO, I.O., YERMOSHYN, M.O., DROBACHA, H.A. and DOLYNA, M.P. Synthesis of Adaptive Structures of the Anti-Aircraft Missile and Artillery Support of Objects and Troops and Assessment of their Effectiveness (in Ukrainian). Kharkiv: KhAFU, 2006. 348 p. ISBN 966-601-086-0.

[3] DELANEY, W.P. Perspectives on Defense Systems Analysis. Cambridge: The Massachusetts Institute of Technology Press, 2015. 288 p. ISBN 978-0-26202935-3.

[4] LEVENTOPOULOS, S.A. Ground-Based Air Defense Systems - New Challenges and Perspective. [Research Paper]. Athens: Research Institute for European and American Studies (Rieas), 2018. 20 p. ISSN: 2241-6358.

[5] KOPP, C. Surviving the Modern Integrated Air Defence System. Air Power Australia Analyses, 2009, vol. 6, no. 2, p. 1-13. ISSN 1832-2433.

[6] KOPP, C. Evolving Technological Strategy in Advanced Air Defense Systems. Joint Force Quarterly, 2010, vol. 57, p. 86-93. ISSN 1070-0692.

[7] ADRP 3-0. Unified Land Operations [on line]. Washington: Headquarters Department of the Army, 2012. 76 p. [cited 2018-11-19]. Available from: https://www.lsu.edu/hss/milsci/resources/adrp3_0.pdf

[8] Countering Air and Missile Threats. [on line]. Joint Publication (JP) 3-01. May 2018. 169 p. [cited 2018-10-16]. Available from: https://www.jcs.mil/Portals/36/ Documents/Doctrine/pubs/jp3_01_pa.pdf?ver=2018-05-16-175020-290

[9] ROMANCHENKO, I.S., ZAHORKA, O.M., BUTENKO, S.G. and DEINEHA, O.V. The Theory and Practice of Antiair Waefare against Pinpoint Low Targets (Assessment of Capabilities, Trends in the Development of Air Defense Assets) (in Ukrainian). Zhytomyr: Polissya, 2011. 344 p. ISBN 978-966-655-594-9.

[10] HORODONOV, V.P., DROBAKHA, H.A., YERMOSHYN, M.O., SMYRNOV, Y.B. and TKACHENKO, V.I. Modeling of Combat Operations of Troops (Forces) of AIR Defense and Information Support of the Processes of Their Management (in Ukrainian). Kharkiv: KhVU, 2004. 409 p. ISBN 966-601-071-2.

[11] SHULEZHKO, V.V., KUZMIN, S.A., RYABOKON, Y.O., KULIESHOV, O. V. and MEHELBEI, V.V. Method of Justification of the Rational Structure of the Anti-Aircraft Rocket-Artillery Support of the Grouping of Air Defense in the Operational Area (Zone) (in Ukrainian). Scientific Works of the Kharkiv Air Forces University, 2015, vol. 4, no. 45, p. 30-35. ISSN 2818-1661. 
[12] LANETSKYI, B.M., LUKIANCHUK, V.V., VASILIEV, V.A. and KOVAL, I.V. The Development of Scientific and Methodological Provisions on the Preliminary Justification of the Quantitative and Qualitative Composition of Anti-Aircraft Missile Armament of the Grouping of Anti-Aircraft Missile Troops (in Ukrainian). Science and Technology of the Air Forces of the Armed Forces of Ukraine, 2012, vol. 3, no. 9, p. 58-60. ISSN 2518-1505.

[13] BODROV, V.I., LAZAREVA, T.Y. and MARTEMIANOV, Y.F. Mathematical Decision-Making Methods (in Russian). Tambov: Publ. Tamb. State Technical University, 2004. 124 p. ISBN 5-8265-0259-2.

[14] PROTTER, M.H. and MORREY, C.B. Jr. Intermediate Calculus. New York: Springer, 1985. p. 655. ISBN 978-1-4612-1086-3.

[15] ABCHUK, V.A., MATVEICHUK, F.A. and TOMASHEVSKY, L.P. Handbook for Operations Research (in Russian). Moscow: Military Publishing, 1979. 368 p.

[16] HILLIER, F.S. and LIEBERMAN, G.J. Introduction to Operations Research. New York: McGraw-Hill, 2010. 1073 p. ISBN 978-0-07-337629-5.

[17] MELENTIEV, P.V. Approximate calculations (in Russian). Moscow: State Physics and Mathematics Publishing House, 1962. 388 p.

[18] STEWART J. Multivariable Calculus: Concepts \& Contexts: Brooks/Cole, 2004. 978 p. ISBN 0-534-41004-9. 